\title{
Algunos aspectos de la figura humana en la pintura de El Greco
}

\author{
Francisco Javier Caballero Bernabé
}

\section{FIGURAS MODELO}

El Greco repite una serie de figuras a lo largo de su producción pictórica cuando se trata del mismo personaje o tema. Así encontramos la figura de santa M. ${ }^{a}$ Magdalena, san Francisco de Asís, santo Domingo de Guzmán, san Pedro, san Pablo, la Virgen, san José, Cristo, los Apóstoles, etc., que aparecen como una constante, como si el cretense hubiese experimentado o tanteado cuál es la imagen que mejor se corresponde con la idea que desea plasmar y cuando la ha obtenido no se molesta en nuevas búsquedas, que considera innecesarias, sino en mínimas variaciones.

Las figuras-modelo aparecen en la etapa italiana. Tanto en las versiones de Washington y Minneapolis de la "Expulsión de los mercaderes del Templo" como en las telas de Parma, Dresde y Nueva York de la "Curación del ciego", afectando a diversas figuras secundarias y principales.

Esta característica se acentuará en la etapa española en numerosos temas ("La Verónica con el velo»; la "Santa Faz"; "San Francisco en extasis"; "Alegoría de la Santa Liga"; "Santa Ma. Magdalena»; etc.). Entre los varios ejemplos destacables por la acumulación de figuras que posteriormente se repetirán por separado o conjuntamente en otras obras señalaremos el caso del "Entierro del señor de Orgaz», donde encontramos las imágenes de Cristo, la Virgen, san Juan Bautista, san Pedro, los ángeles, los apóstoles en general. Figuras que se mantendrán de forma invariable o, en el mejor de los casos, sufrirán una leve evolución. Curiosamente muchas de ellas es la primera vez que aparecen en la obra del cretense y otras marcan un punto de ruptura con las representaciones anteriores.

En los cuadros donde el número de personajes es elevado se observan figuras repetidas, tanto en lo que se refiere a rostros, como a las 
posturas que adoptan. La repetición de figuras es también una constante. Este aspecto que ha sido estudiado por la mayoria de los críticos es objeto de análisis en una obra de Allen ", donde demuestra que las angulosidades y deformaciones de las distintas partes del cuerpo humano son iguales en brazos, tronco y piernas, y están colocadas en los mismos puntos. Lo cual no es extraño si como afirma Pacheco, El Greco poseía en su estudio figuras de barro ${ }^{2}$. Los ejemplos a este respecto son múltiples. Cabe suponer que este hecho favorecía que el artista trabajase más deprisa, sin obviar que los clientes podían estar demandando esos tipos en concreto.

Otra caracteristica que encontramos en los santos es que El Greco asigna a cada uno de ellos unos colores determinados. Santo Domingo de Guzmán viste el hábito de la orden dominica fundada por él. Santa M. ${ }^{\text {a }}$ Magdalena sufre una evolución en los colores pero termina siendo el suyo característico, el rojo-anaranjado. San Pedro, el amarillo y el verde. La Virgen, el azul y rosa carmín. San José muestra mayor variedad, pero destaca el amarillo y verde.

\section{EL CANON Y LAS POSTURAS}

El canon de las figuras ofrece una evolución con dos períodos claramente diferenciados.

En la etapa italiana las figuras tienen un canon más cercano al clásico de siete cabezas y media, nunca exacto, ya que tienden a algo más.

En el período español, desde el primer momento, ese canon se estiliza y alarga creciendo la desproporción manierista del mismo, hasta alcanzar la figura, en su última etapa, una proporción de once o más cabezas.

En la época española disminuye el tamaño de la cabeza en una acentuada microcefalia.

El estudio del cuerpo humano en el período italiano alcanzaba connotaciones miguelangelescas y en algunas obras de las primeras realizadas en Toledo, como la figura de Cristo de la "Trinidad", el "San Sebastián" de la catedral de Palencia, etc. (fig.1). En el período español tiende a disminuir, en parte porque la línea que demarcaba los perfiles se forma ex-

AlleN, G.R.: El Greco two studies. John F. Warren. Philadelfia, 1984.

PACHECO, F.: Arte de la pintura, su antigüedad y grandeza. Sevilla, 1649. Madrid, 1956. 
clusivamente por los colores y con ello pierde nitidez, también influye en ello la evolución técnica en la manera de pintar.

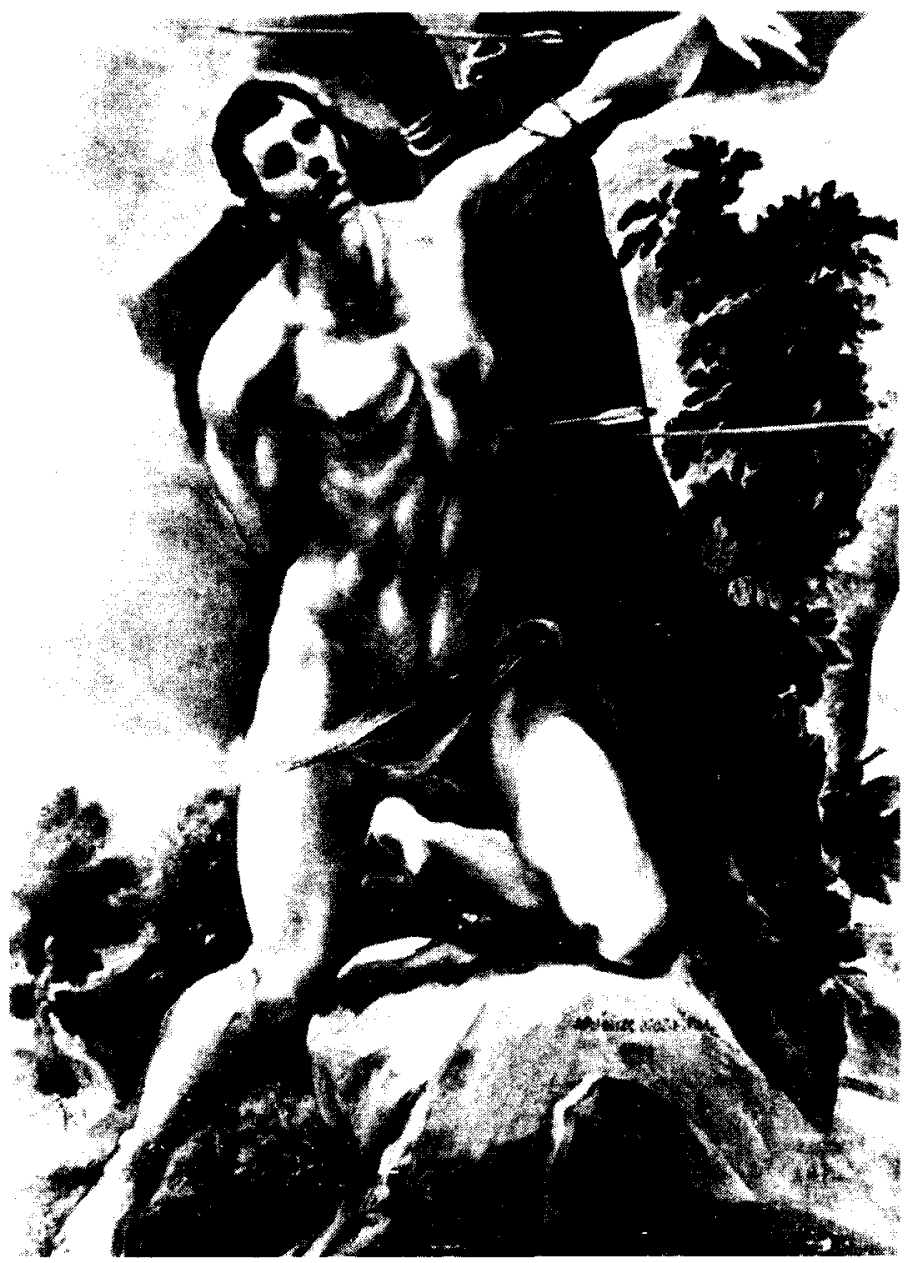

Fig. 1. “San Sebastián” (1576-79). Catedral de Palencia.

Para acentuar la expresividad de la figura, el cretense recurrirá de forma constante a la deformación anatómica y a la desproporción.

El punto de vista bajo de la composición alarga la ya de por si esbelta figura acentuando el canon manierista y la microcefalia.

Desde las primeras versiones de la "Curación del ciego" o la “Expulsión de los mercaderes del Templo» (fig.2), las figuras de El Greco van a adoptar posturas que son características del manierismo, 
como la linea serpentinata, el contrappostol, las posiciones inestables e incluso absurdas, como las de algunos personajes sentados no se sabe bien dónde. En el caso de las nubes, estas se semejan más a rocas que a masas algodonosas, creando la sensación de espacio como ningún otro elemento.

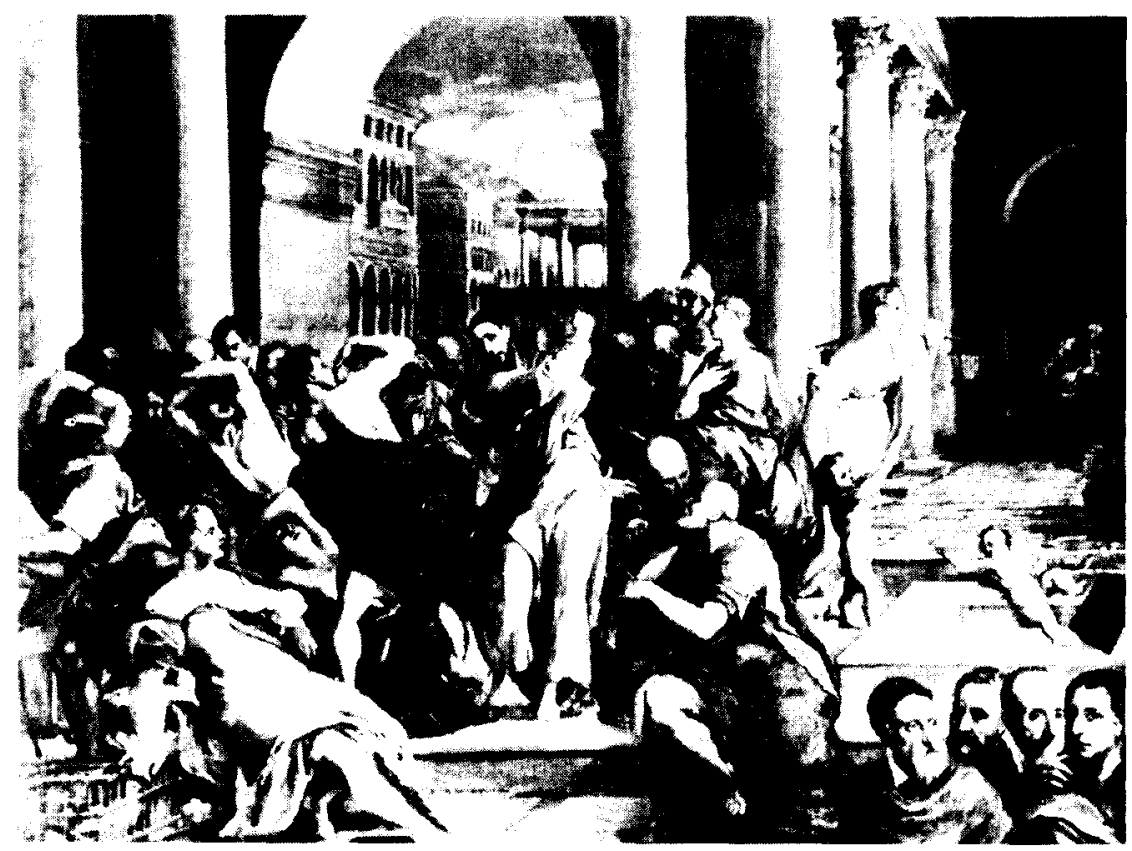

Fig. 2. "Expulsión de los mercaderes del templo» (1570-75)

Aparecen las primeras actitudes que contribuirán a dar la sensación de un canon más estilizado, por medio de los brazos estirados o doblados con la mano abierta; una pierna más atravesada que la otra; una recta, mientras la otra se flexiona levemente. Los ejemplos son múltiples, cada figura reúne una o varias de estas características.

En España, estos recursos expresivos se acentúan, llegando a un expresionismo extremo, radicalizado, con escorzos atrevidos y violentos, cuyos ejemplos más significativos tal vez sean algunas figuras del "Martirio de San Mauricio y la Legión Tebana", san Juan Bautista del "Entierro del señor de Orgaz", Cristo en las distintas versiones de la «Crucifixión», el conjunto de personajes que aparecen en la "Expulsión de los mercaderes del Templo», "Bautismo de Cristo", "Laocoonte», 


\section{LAS MANOS Y LOS ROSTROS}

Las deformaciones anatómicas no van a ser el único medio para obtener expresividad en las figuras; junto a la falta de simetría de los personajes, los desequilibrios aludidos y las posiciones inestables e imaginarias, no factibles en la realidad, hay que añadir el papel desempeñado por los rostros y las manos.

El canon conferido a las alargadas y estilizadas manos es de gran finura, tanto que éstas pierden la característica propia del sexo masculino o femenino del personaje a que pertenecen, tendiendo siempre hacia lo femenino.

Las manos desarrollan una función activa y de gran importancia, son focos de atención del espectador, y expresan a través de las más variadas posiciones toda una conversación de frases breves, directas, claras, concisas, tanto interrogativas y explicativas como exclamativas, reflejan los más variados sentimientos y sensaciones, su estudio se ha denominado gestáltica. En el cuadro el "Martirio de San Mauricio y la Legión Tebana» las posiciones de las manos ponen de manifiesto la serena conversación de los protagonistas y la diversidad de opiniones (fig.3).

La misma categoría alcanzan los rostros, asimétricos, gesticulantes, de facciones incorrectas en muchos casos para acentuar ese expresivismo, fiel reflejo del mundo psicológico, intelectual y espiritual, que experimenta el ser humano ante los más variados acontecimientos. En otras ocasiones, las menos, caso del «Martirio de San Mauricio y la Legión Tebana» los rostros tienen facciones regulares y se busca la belleza, que la representan a través de la serenidad y la delicadeza. No hay tensión ni dramatismo, sino transparencia del mundo interior.

El Greco ha recogido, plasmado y analizado, toda una amplia gama de estas respuestas, lo que supone una interiorización del individuo o autointrospección, capacidad de análisis profundo y un proceso de intelectualización elevado.

La amplitud de los modelos no implica que estos rostros no se repitan a lo largo de su dilatada carrera, como si el mundo interior y las inquietudes que los animan no cambiasen pese a transcurrir el tiempo.

Cada uno de los elementos del rostro, ojos, labios, nariz, orejas, barbiIla, frecuentemente oculta en los hombres por la barba, tiene por sí mismo la importancia que adquiere el rostro en su conjunto, aunque también frecuentemente presenta incorrecciones, que contribuyen a formar un todo armónico, cumpliendo su función expresiva. 


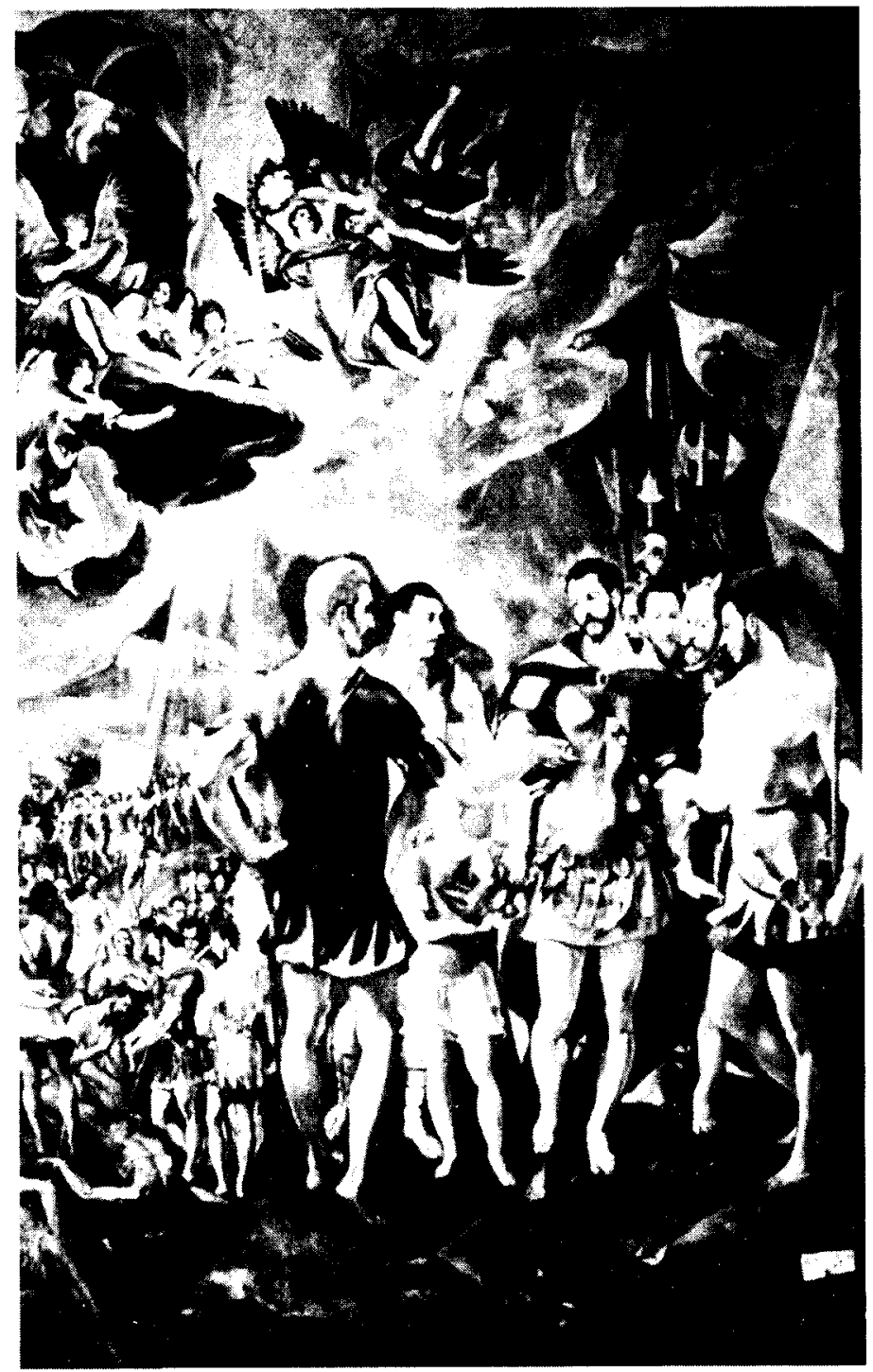

Fig. 3. "Martirio de San Mauricio y la Legión Tebana" (1580-82). Monasterio de El Escorial (Madrid).

Los ojos son, sin duda, el elemento del rostro que más ha atraido la atención de los críticos, ya que presentan una particularidad no bien explicada hasta el momento, el ojo derecho aparece más redondeado, circular, semejando a lo que se ha denominado "ojo de búho", mientras el izquierdo se acerca más a la característica forma almendrada. 
La dirección de las miradas es utilizada como recurso pictórico para llamar la atención de los espectadores sobre un personaje o acontecimiento. Al igual que las manos, también existe un diálogo a nivel de las miradas de los protagonistas como en el caso de la "Anunciación» del M. del Prado (fig.4).

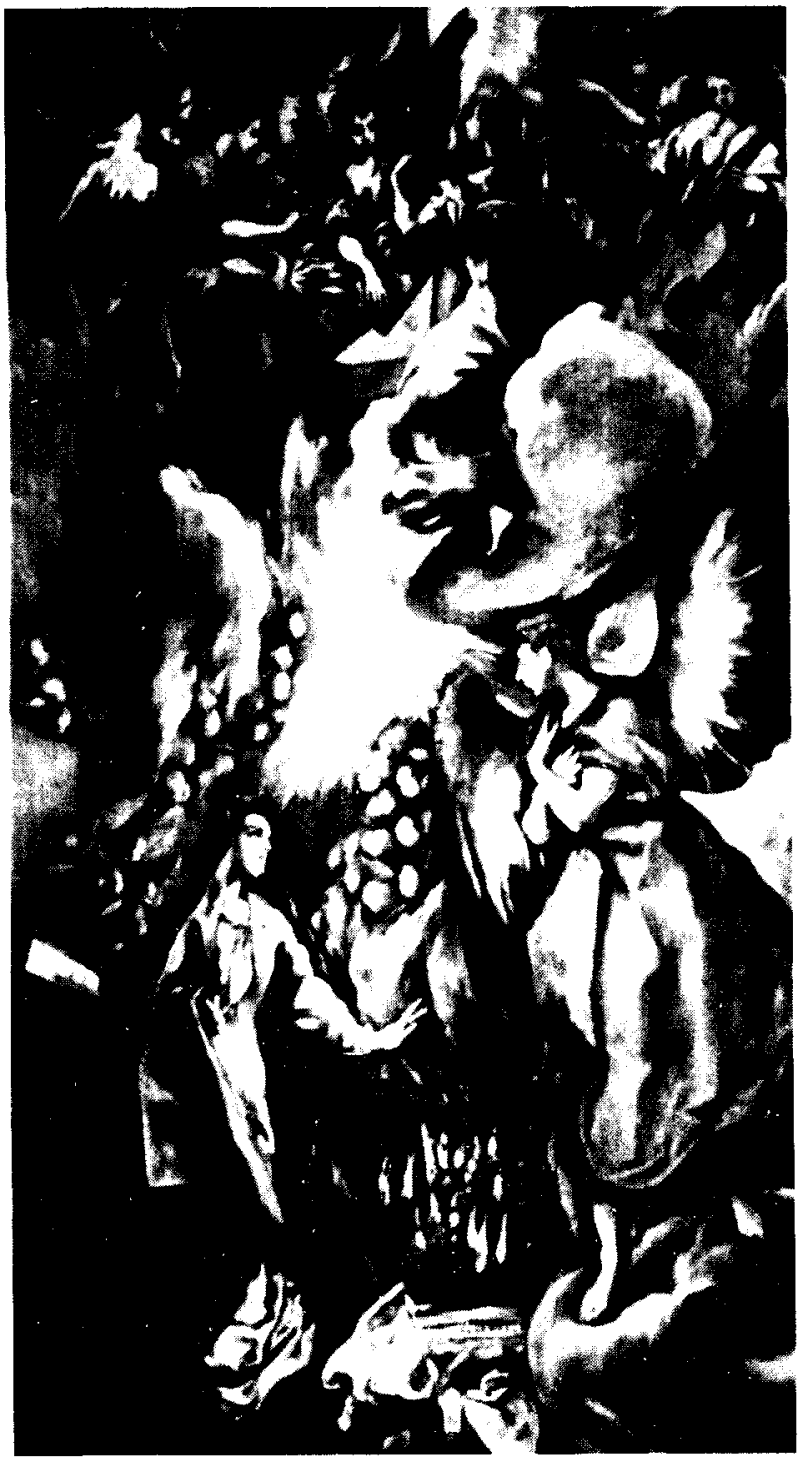

Fig. 4. "Anunciación" (1596-1600). Museo del Prado. Madrid, antes en Villanueva y la Geltrú. 


\section{EL VESTUARIO}

El ropaje juega un papel destacado cuando éste cubre total o parcialmente las figuras.

El vestuario es un ropaje amplio, atemporal, compuesto de mantos y túnicas, que envuelven a las figuras con los más caprichosos plegados de los paños y que confieren movimiento, a veces trepidante, de manera que consigue formar parte del todo homogéneo que contribuye a definir la personalidad e individualidad de cada uno de los personajes. A veces, el ropaje envuelve de tal manera la figura que ésta desaparece bajo las telas, caso de la "Visitación»; en otras, a través de ellas se vislumbra la anatomía del personaje, como los ángeles y otras figuras de diversos temas; también los ropajes pueden aparecer como elemento accesorio que contribuyen a centrar la escena, a realzar la figura principal, como en el caso de Cristo en la "Oración en el huerto".

El vestuario es en ocasiones anacrónico como es observable en la "Curación del ciego" y la "Expulsión de los mercaderes del Templo", ambas de época italiana, pues se mezclan personajes con amplios ropajes con figuras vestidas a la usanza del s. xvI. Este anacronismo es más acusado en el "Martirio de San Mauricio y la Legión Tebana", ya que el autor ha mezclado, en las vestimentas de los soldados, corazas pseudorromanas de cuero, que en realidad parecen camisas que van pegadas al cuerpo y transparentarı toda la anatomía, con armaduras y celadas similares a las que se usaban en la época del artista. Este mismo fenómeno se observa en el armamento al mezclarse picas y espadas del s. XVI con una espada granadina.

En el caso de los santos pertenecientes a órdenes religiosas, por lo general, el hábito se corresponde con el propio de la orden religiosa. San Francisco de Asís muestra en el hábito una peculiaridad que ya señalara Pacheco ${ }^{3}$, pues es una interpretación personal que se acerca a las ramas franciscanas de san Pedro de Alcántara y de los Capuchinos. En este último caso no deja de ser paradójico, ya que dicha Orden no se extendió en España hasta el s. XVII, aunque bien pudo conocerla el cretense durante su estancia en Italia.

El contraste de los colores de las telas es violento, no busca El Greco 
los pigmentos complementarios, sino el choque de unos con otros, siendo parte importante para crear la sensación de tensión, movimiento, agitación, etc.

Los retratos de El Greco son fiel reflejo de la moda de la época, la cual aprisionaba el cuerpo y reducia los movimientos, obligando a la cabeza a permanecer siempre erguida, lo que favorecía los movimientos graves, sosegados y altivos, según pone de manifiesto Carmen Bernis ${ }^{4}$. El jubón es la prenda más característica de la época, juntamente con las calzas, la capa y los cuellos o lechuguillas.

El jubón tendía a inscribir la silueta de las personas en un triángulo. Por la parte delantera se abombaba para adaptarse al torso, y las mangas eran ceñidas. El abombamiento era por influencia del traje militar.

El jubón se forraba con lienzo o con tafetán, y se rellenaba de estopa, lana o algodón ${ }^{5}$.

Las lechuguillas, cuellos o cabezones, son los vulgarmente llamados golas y gorgueras, nombres equivocados, como señala Bernis ${ }^{6}$, ya que estos nombres hacen alusión a una pieza de la armadura y al adorno del cuello y pechos de la mujer, respectivamente. Las lechuguillas evolucionaron a lo largo del s. XVI y principios del XVII. Estaban hechas de fino lienzo o de encaje, y por el tamaño de las mismas podemos tener una referencia cronológica aproximada sobre la fecha de realización del retrato.

A partir de 1557 las lechuguillas, que eran pequeñas, rozan ligeramente las orejas, y este tamaño se mantiene a lo largo de la década de los sesenta.

Hacia 1570 el cuello sube un poco más, por la parte posterior de la cabeza, quedando las orejas apoyadas en él, aunque aún siguen estas sobresaliendo de la lechuguilla por su parte más alta; manteniéndose la moda hasta cerca de 1590 (fig.5).

Posteriormente a esta fecha, los cuellos ensanchan su diámetro y suben por detrás, sobrepasando a las orejas. A finales de siglo se convirtieron en enormes plataformas, por lo que necesitaron su soporte, llamado el alzacuello, que era de cartón y se forraba de tela.

Catálogo de la Exposición Alonso SAnchez Coello. "La moda en la España de Felipe ll a traves del retrato de corte». M. de Cultura Madrid, 1990, pág. 66.

BEFINIS, C.: Ob. cit., pág. 68.

Ob. cit., pág. $80-81$ 


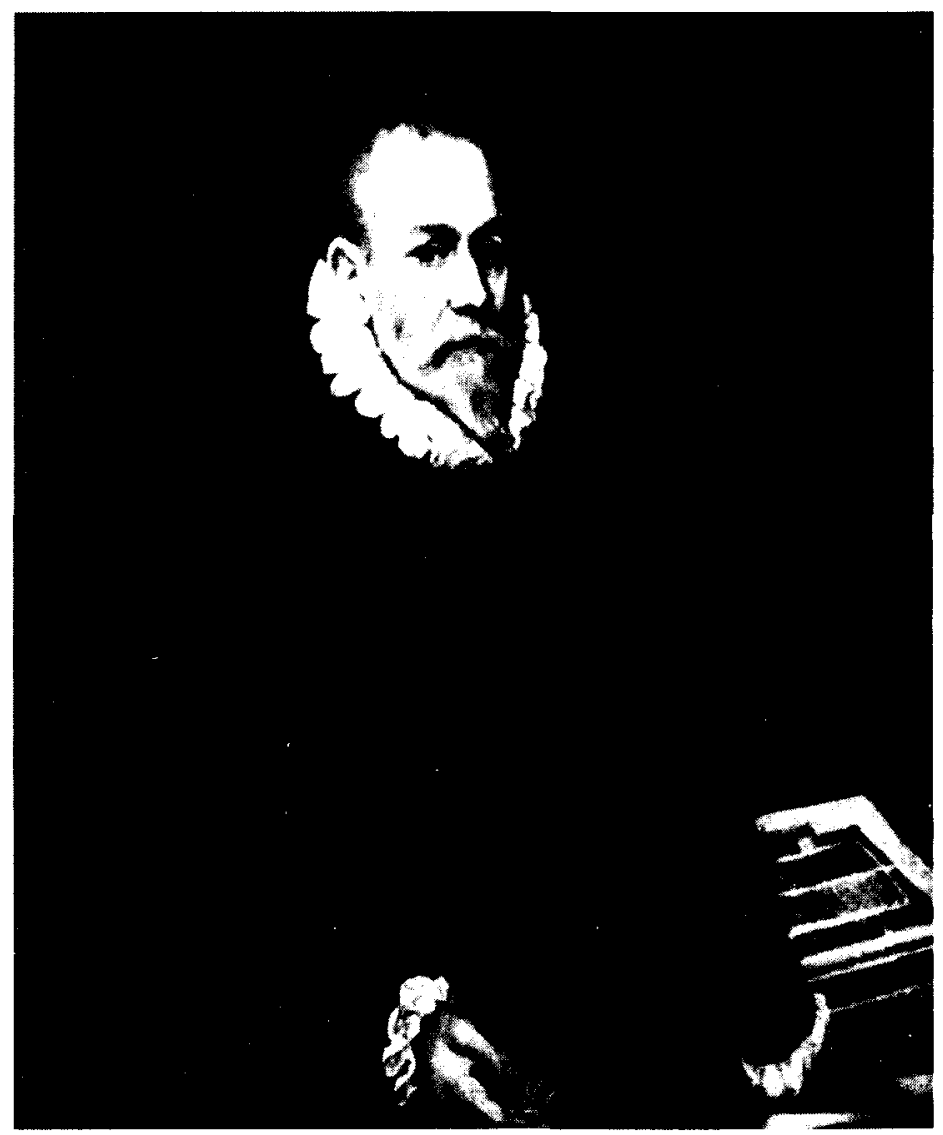

Fig. 5. "Doctor Rodrigo de la Fuente» (1585-89). Museo del Prado. Madrid)

\section{LA FIGURA EN SI MISMA Y EN RELACION CON EL CUADRO}

Al cretense le interesa más plasmar la vida y tensión interior, psicológica y espiritual, de los seres humanos que la perfección técnica del acabado minucioso y detallístico, propio de la corriente opuesta a la que él defiende y en la que el dibujo predomina sobre el color.

La vida interior, la inquietud, se manifiesta por el movimiento que parecen contener en si mismas las figuras y que traducen al exterior a través de los escorzos y giros violentos de las distintas partes del cuerpo, hasta situaciones extremas, en la intensidad de los rostros y las manos, en lo nervudo de la figura, la estilización y el canon alargado. Pocas son las figuras que aparecen en reposo y quietud, salvo los re- 
tratos individuales y colectivos, las vírgenes y algunas figuras de santos. Al mismo tiempo se puede afirmar que pocas de ellas están en movimiento. Por ello, cabe indicar que las figuras aún sin moverse implican movimiento. Hay una falta de acción y, al mismo tiempo, el reposo y la quietud tienden a desaparecer por la inestabilidad de las posturas, ya que estas suponen una tensión, un esfuerzo psicológico que inmediatamente se manifiesta al exterior y que impide a la figura permanecer en esa posición más allá de unos instantes. Las figuras parecen recoger instantáneas fotográficas.

Las figuras de El Greco son seres de vida intensa, que rara vez les permite permanecer recogidos en sí mismos. Tienden a la comunicación con los demás personajes del cuadro, y; cuando son figuras solitarias se comunican con elementos que se encuentran fuera del cuadro, y que el espectador puede o no contemplar. Lo cual a su vez crea una tensión y un interrogante acerca de la identidad de la figura invisible y del fenómeno que se está produciendo y la intensidad del mismo. Dado la preponderancia de los temas religiosos, estos fenómenos adquieren un carácter espiritual, entablándose un diálogo por medio de la mirada, los gestos y las posturas en general de la figura. Un ejemplo seria el retablo de Santo Domingo el Antiguo de Toledo. También existe la comunicación con el espectador, para ello se vale de los mismos elementos expresivos señalados, aunque interpretados de manera diferente.

Muchas figuras de ángeles y santos van descalzas, aspecto que en la antigüedad clásica era simbolo de divinidad.

Todos los elementos, el color, la luz, los esquemas compositivos, las telas, las posturas, etc., contribuyen a crear el volumen en la figura, que al principio de la carrera pictórica de El Greco aparece con más rotundidad y más claramente delimitado, características que poco a poco va perdiendo para fundirse con otros elementos de los cuadros o con el fondo cromático de los mismos. En la época final la figura tiende a la desmaterialización por medio de la luz y el color "; buen ejemplo de ello son las obras realizadas en los últimos años, "Visitación", "San Jerónimo penitente» ejemplar de Washington, "Desposorios de la Virgen», etc.

En muchos casos se llega a la pérdida de la identidad sexual de los personajes. Un claro ejemplo lo encontramos en las múltiples interpretaciones

Caballero Bernabe, F.J.: La pintura de El Greco y la literatura ascético-mistica española del siglo Xvl. Univ. Complutense. Madrid, 1991 (Tesis doctoral). Edición de la Caja de Castilla La Mancha. Madrid, 1994. 
que han sufrido los espectadores de la muerte de Laocoonte y sus hijos en el cuadro de "Laocoonte», hasta que Vetter identificó a Paris y Helena ${ }^{8}$. De forma particular también es observable en las figuras de los ángeles del "Bautismo de Cristo" y en los cuerpos que recogen las telas de vivos colores en “El Quinto Sello del Apocalipsis» (fig.6), entre otros ejemplos.

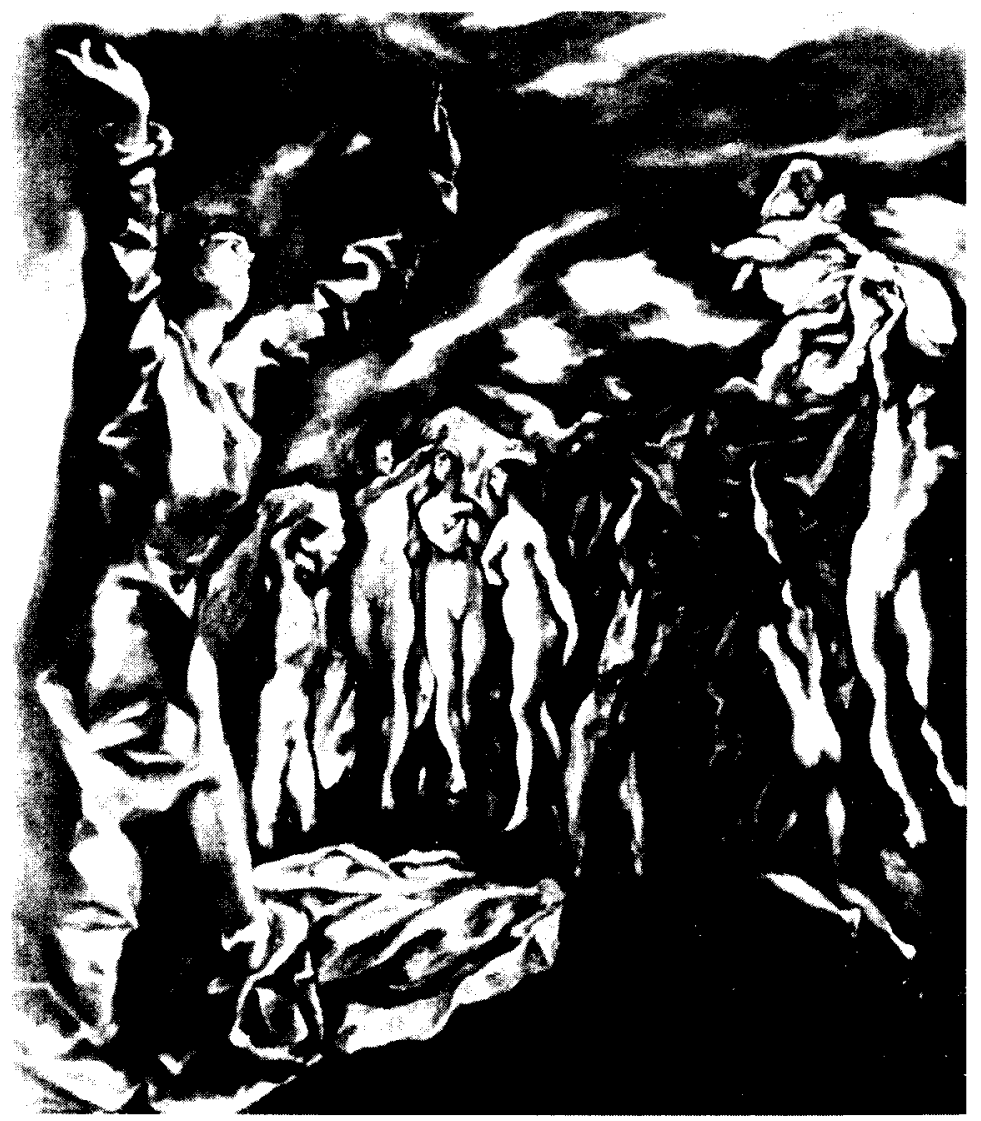

Fig. 6. "El Quinto Sello del Apocalipsis" (1608-14). Metropolitan Museum de Nueva York.

La figura abarca por lo general la mayor parte de la superficie pictórica y también ocupa el lugar más destacado.

\& Vetter, E.M.: “El Greco's -Laokoon-Reconsidered". Pantheon, 27, 4, Jul.-Ag., 1969, págs. 298-299. 
La figura humana es esencial en la pintura del cretense, es el elemento de su máxima atención, llegando a sustituir el entorno y paisaje por las figuras, como en el "Bautismo de Cristo».

El plantear la escenografía como un primer plano y luego un vacío entre éste y el paisaje o aparato escénico, que ocupa una extensión mínima y aparece alejada en el espacio, hace que la figura humana y el tema principal con ella se desarrolle en el primer plano inmediato al espectador, aunque a veces existe entre ambos un espacio amplio e incluso unas figuras que introducen al espectador en la escena. Figuras que sugieren una relación e influencia del teatro en la pintura, lo mismo que ocurre con toda la gestáltica de tan amplio desarrollo, es decir las figuras interpretan, y si a esto añadimos las posiciones inestables que nos sugieren un cambio de postura inmediato o la sucesión de otras escenas, estaríamos ante instantáneas de tipo fotográfico.

Rara vez la escena principal se desarrolla en un segundo plano o plano intermedio, como en la "Oración en el Huerto» de Andújar. Característica ésta manierista que apenas emplea.

La doble escenificación, es decir la representación de una escena en la tierra y otra simultánea en el cielo, unido a la desmedida altura de los personajes, hace que el cuadro tienda en sus dimensiones a ser más alto que ancho, llegando a estar esta proporción en más de dos a uno en algunas obras. Es decir la escenificación se desarrolla tanto en profundidad como en altura, incluso tiende a ser preponderante esta última, pues las obras de El Greco se encaminan paulatinamente a la pérdida de la profundidad y por lo tanto a una cierta planitud.

La distribución de la figura o figuras en la escena tiende a un equilibrio o una compensación de las distintas formas y masas, esto mismo se podría afirmar de los colores. Aunque esta no es de tipo renacentista, la figura principal tiende a ocupar el centro, o al menos existen elementos que la señalan, como en el caso del «Bautismo de Cristo" o la "Adoración de los pastores".

Las figuras se distribuyen en las escenas por medio de diversos esquemas, circulares, líneas horizontales, verticales y oblicuas, pirámides, vértices, etc., con frecuencia se da la superposición de esquemas en la misma escena si intervienen varias figuras, como en la "Resurrección», "Pentecostés", "Adoración de los pastores", etc.

Existe también una adaptación de la figura al espacio, lo que se observa claramente en ias obras con forma de tondo del Hospital de la Caridad de lllescas, entre otras. 


\section{EL CONCEPTO DE BELLEZA}

Se ha señalado por parte de varios críticos que la figura humana en $E$ I Greco muestra una influencia de la corriente neoplatónica ${ }^{9}$ en cuanto a la búsqueda de la belleza.

Conviene analizar el sentido de "lo bello" y la relación con esta filosofía. Tradicionalmente se ha considerado a Botticelli, Rafael de Urbino y Miguel Angel como los máximos representantes de esta concepción estética de carácter neoplatónico. Al contemplar sus obras, observamos que en ellas predomina el dibujo sobre el color, y que las figuras humanas son prototípicas de lo masculino y lo femenino. Características contrarias a las que se observan en la obra de El Greco, como consecuencia difícilmente se armoniza este aspecto del neoplatonismo con la obra del cretense.

No se puede afirmar que en las obras del cretense no exista una búsqueda de la belleza, pues encontramos una idealización del cuerpo humano, pero tal vez sería más exacto decir que existe otra concepción estética de la belleza, otros presupuestos que, desde luego, no coinciden con los plasmados por los artistas señalados más arriba, ni siquiera con otros artistas manieristas del s. XvI como Parmigianino, Bronzino, etc., donde la plasmación de la belleza es patente en las formas.

De los rostros en particular, se puede decir que salvo contados casos, como los de la Virgen en algunas Sagradas Familias, Anunciaciones, etc., no son bellos, y lo mismo se puede aplicar a los cuerpos; pues los elementos que componen unos y otros no guardan proporción entre ellos, mostrando deformaciones o exageraciones evidentes.

Por ello, se puede concluir que la belleza en la pintura de El Greco está sacrificada a la capacidad del cuerpo humano para obtener la máxima expresividad. La existencia de unos modelos que se repiten en muchos temas indica una búsqueda del artista para encontrar una fórmula ideal con la cual expresar un mensaje, pero se observa que el modelo último no implica una figura estéticamente bella.

Objetivamente las figuras masculinas de El Greco son más bellas, atractivas y perfectas que las femeninas, lo cual enlazaría con el ideal clásico de belleza, que lo constituia el hombre y no la mujer. Sin embargo, por encima de estos dos cánones hay que situar las figuras de los ángeles

Marias, F. - Bustamante. A.: Las ideas artísticas de El Greco. Comentarios a un texto inédito. Cátedra. Madrid, 1981. Brown, J.: Visiones del pensamiento. Estudios sobre El Greco. Alianza. Forma. Madrid, 1984. 
de ambigua sexualidad, que resultan estéticamentemás bellas y sugerentes, y que nos recuerdan a los efebos clásicos, aunque aqui la razón de su ambigüedad sea muy distinta y no se busque la sensualidad, sino el plasmar un principio dogmático, los ángeles no tienen sexo. 
